\title{
Glucagon lowers glycemia when $\beta$ cells are active
}

\author{
Megan E. Capozzi, ${ }^{1}$ Jacob B. Wait, ${ }^{1}$ Jepchumba Koech, ${ }^{1}$ Andrew N. Gordon, ${ }^{1}$ Reilly W. Coch, ${ }^{1,2}$ \\ Berit Svendsen, ${ }^{1}$ Brian Finan, ${ }^{3}$ David A. D'Alessio, ${ }^{1,2}$ and Jonathan E. Campbell ${ }^{1,2,4}$ \\ 'Duke Molecular Physiology Institute and 'Department of Medicine, Duke University, Durham, North Carolina, USA. \\ ${ }^{3}$ Novo Nordisk Research Center, Indianapolis, Indiana, USA. ${ }^{4}$ Department of Pharmacology and Cancer Biology, Duke \\ University, Durham, North Carolina, USA.
}

\begin{abstract}
Glucagon and insulin are commonly believed to have counteracting effects on blood glucose levels. However, recent studies have demonstrated that glucagon has a physiologic role to activate $\beta$ cells and enhance insulin secretion. To date, the actions of glucagon have been studied mostly in fasting or hypoglycemic states, yet it is clear that mixed-nutrient meals elicit secretion of both glucagon and insulin, suggesting that glucagon also contributes to glucose regulation in the postprandial state. We hypothesized that the elevated glycemia seen in the fed state would allow glucagon to stimulate insulin secretion and reduce blood glucose. In fact, exogenous glucagon given under fed conditions did robustly stimulate insulin secretion and lower glycemia. Exogenous glucagon given to fed Gcgr:Glp1 $r^{\beta c e l l-/-}$ mice failed to stimulate insulin secretion or reduce glycemia, demonstrating the importance of an insulinotropic glucagon effect. The action of endogenous glucagon to reduce glycemia in the fed state was tested with administration of alanine, a potent glucagon secretagogue. Alanine raised blood glucose in fasted WT mice or fed Gcgr:Glp1 $r^{\beta c e l l-/-}$ mice, conditions where glucagon is unable to stimulate $\beta$ cell activity. However, alanine given to fed WT mice produced a decrease in glycemia, along with elevated insulin and glucagon levels. Overall, our data support a model in which glucagon serves as an insulinotropic hormone in the fed state and complements rather than opposes insulin action to maintain euglycemia.
\end{abstract}

Conflict of interest: $\mathrm{BF}$ is an employee of Novo Nordisk.

Copyright: () 2019, American Society for Clinical Investigation.

Submitted: April 30, 2019

Accepted: July 18, 2019

Published: August 22, 2019.

Reference information: /CI Insight. 2019;4(16):e129954. https://doi. org/10.1172/jii.insight.129954

\section{Introduction}

One of the islet defects often attributed to people with type 2 diabetes (T2D) and hyperglycemia is inappropriately high glucagon level in both the fasting and postprandial states (1). The canonical view of glucagon is focused on $\alpha$ cell secretion in response to hypoglycemia or fasting and counter-regulatory effects balancing insulin action to maintain euglycemia. However, a mixed-nutrient meal induces a rise in circulating glucagon in nondiabetic individuals $(2,3)$ as well as people with T2D (4), suggesting that glucagon may have physiologic actions in the postprandial state. In support of this, we recently demonstrated that glucagon signaling to $\beta$ cells is essential for dictating cellular tone and function (5), and others have shown that glucagon secretion is a major determinant of the glycemic set point of several mammalian species (6). Indeed, glucagon shares a similar characteristic with the incretin peptides, glucose-dependent insulinotropic polypeptide (GIP) and glucagon-like peptide 1 (GLP-1), potentiating insulin secretion at elevated glucose levels but with little activity at low glucose levels (5). This restriction of glucagon to stimulate insulin secretion in a glucose-dependent manner is a feature of class B G protein-coupled receptors expressed by $\beta$ cells that signal primarily through cAMP. Interestingly, although $\beta$ cells express insulinotropic glucagon receptors (GCGRs), glucagon primarily stimulates insulin secretion in mouse and human islets through the GLP-1 receptor (GLP-1R) (5, 7).

The best characterized glucoregulatory actions of glucagon are described in the liver, where glucagon increases glucose production by stimulating glycogenolysis and gluconeogenesis (8). However, these hepatic actions have predominantly been studied in the fasted state, coinciding with the perception that glucagon is primarily a counter-regulatory hormone. The relatively low levels of glycemia in the fasted state minimize the insulinotropic actions of glucagon, obscuring any effects on $\beta$ cells, while leaving hepatic actions of glucagon as the principal determinant of blood glucose. Whether glucagon action in activated $\beta$ cells elicits a different effect on glycemia in the fed state is unknown. This has important implications for 
the pharmacology of glucagon action because numerous efforts are now being made to incorporate GCGR activity into multireceptor agonists (MRAs) to treat diabetic hyperglycemia (9). To date the primary goal of adding glucagon activity to novel MRAs is to promote energy expenditure and reduce food intake, with the caveat that hepatic effects could worsen hyperglycemia. Combining glucagon activity with GLP-1R $(10,11)$ or GLP-1R/GIPR (12-14) activity theoretically provides sufficient insulin secretion to buffer the hyperglycemic tendencies of glucagon (9). However, these are mostly theoretical assumptions, and the role of glucagon activity in MRAs has not been carefully parsed.

In the present study, we hypothesized that the glycemic effect of glucagon is dependent on the state of $\beta$ cell activation and that during meals, when blood glucose is elevated, glucagon-stimulated insulin secretion would become as important as glucagon-stimulated hepatic glucose production. Herein, we demonstrate that delivery of exogenous glucagon at sufficient concentrations to engage $\beta$ cell activity or delivery of alanine to stimulate endogenous glucagon secretion actually causes an incretin-like decrease in glycemia, mediated by a significant increase in insulin secretion. Using genetic and pharmacologic manipulations, we demonstrate that activation of the $\beta$ cells is the crucial determinant for the glycemic response to glucagon. Finally, we demonstrate that glucagon activity in $\beta$ cells is predominantly mediated by GLP-1R activity.

\section{Results}

Glucagon-stimulated insulin secretion is dose-dependent. To test the effect of exogenously delivered glucagon on glycemia in a fed state, we first determined conditions that can effectively trigger $\beta$ cell activity and initiate insulin secretion. A standard glucagon tolerance test uses $10-20 \mu \mathrm{g} / \mathrm{kg}$ given intraperitoneally (i.p.) following a 5- to 18-hour fast (15-17). Under these conditions, glucagon increases glycemia with no appreciable changes in circulating insulin, consistent with its classical counter-regulatory activities. However, fasting conditions do not permit GPCR engagement of $\beta$ cell activity. We demonstrated this by administering the GLP-1R agonist exendin-4 (Ex4) either following a fast, with ambient plasma glucose levels of approximately $70 \mathrm{mg} / \mathrm{dL}$, or under ad libitum conditions, with glycemia approximately $150 \mathrm{mg} / \mathrm{dL}$ (Supplemental Figure 1; supplemental material available online with this article; https://doi.org/10.1172/jci. insight.129954DS1). Ex4 failed to alter glycemia under fasting conditions but produced a robust decrease in glycemia under ad libitum conditions, in keeping with the glucose-dependent actions of GLP-1R in $\beta$ cells (18). To test the effect of glucagon in $\beta$ cell activity, we first administered a $20 \mu \mathrm{g} / \mathrm{kg}$ dose during ad libitum feeding with mean starting blood glucose of approximately $150 \mathrm{mg} / \mathrm{dL}$. In this setting glucagon elevated glycemia (Figure 1A), without any detectable effect on insulin secretion (Figure 1B). Given our previous finding that glucagon is a potent insulin secretagogue (5), we reasoned that the dose of glucagon was not sufficient to engage $\beta$ cell activity. When the experiment was repeated using a dose of $1 \mathrm{mg} / \mathrm{kg}$ in ad libitum conditions, blood glucose was reduced (Figure 1C) coincident with an approximately 3-fold increase in circulating insulin concentrations (Figure 1D). These data indicate that sufficient glucagon activity in $\beta$ cells is able to elicit a net decrease of glycemia in the fed state.

Glucagon-stimulated insulin secretion is dependent on $\beta$ cell activity. Based on our findings that glucagon lowers glycemia in the prandial state, we hypothesized that the dichotomous action of glucagon on glycemia is dependent on activation of the $\beta$ cell. However, it is also possible that additional factors, such as the difference in the metabolic state of fasting versus fed or the higher dose of glucagon, could determine the glycemic effects, independently of the level of $\beta$ cell activation. To test this, we used several complementary approaches to directly test the contribution of $\beta$ cell activity to the glycemic effects of glucagon. First, we tested the $1 \mathrm{mg} / \mathrm{kg}$ dose of glucagon in the fasted state, where ambient glucose of approximately $75 \mathrm{mg} / \mathrm{dL}$ limits insulinotropic GPCR activity (Supplemental Figure 1). Under these conditions, glucagon rapidly increased glycemia in the first 10 minutes, followed by a plateau or slight decrease in glucose concentrations (Figure 2A). Interestingly, glucagon induced a modest increase of insulin secretion at 10 minutes (Figure 2B), which was muted compared with the same test under fed conditions (Figure 1D). The small rise in insulin secretion may be responsible for the plateau and slight decrease in glycemia seen in the time points after 10 minutes. However, these data show that $1 \mathrm{mg} / \mathrm{kg}$ of glucagon given in the fasted state produces a net increase in glycemia, in line with the counter-regulatory actions of glucagon often described with $20 \mu \mathrm{g} / \mathrm{kg}$ doses (15-17).

Next, we looked to test the effects of glucagon in the fasted state but in the presence of activated $\beta$ cells. To accomplish this, we coadministered glucagon with glucose given at $33 \%$ of a standard glucose tolerance test dose $(0.5 \mathrm{mg} / \mathrm{kg})$. This amount of glucose was sufficient to elevate glycemia to postprandial 
A
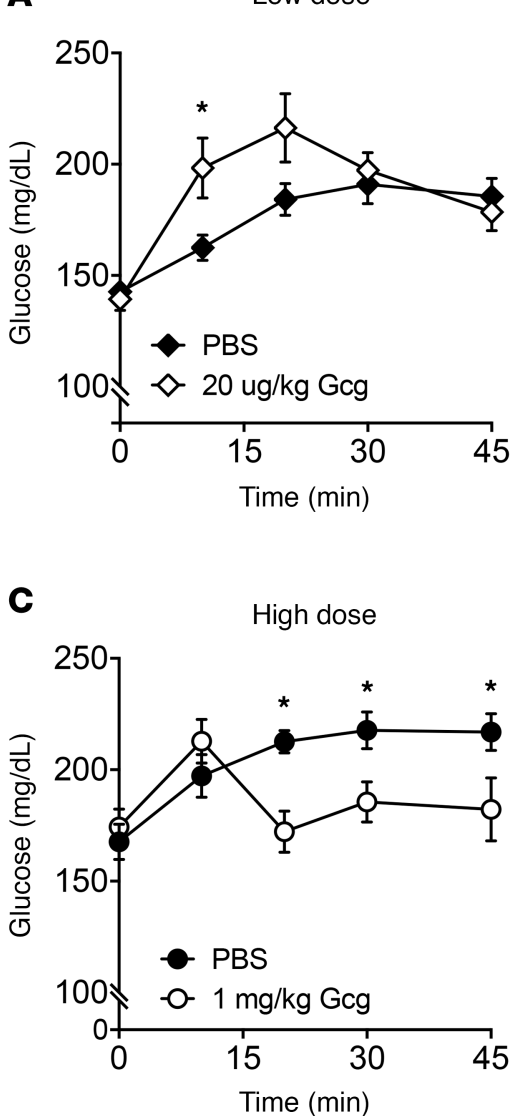

B
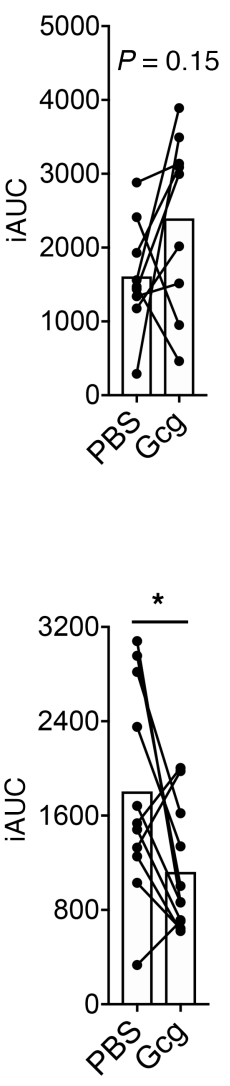

D
PBS
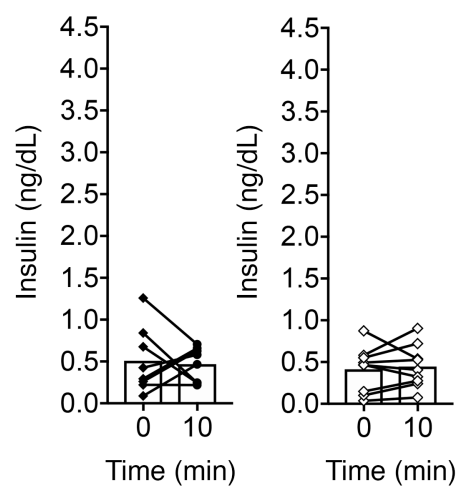

PBS

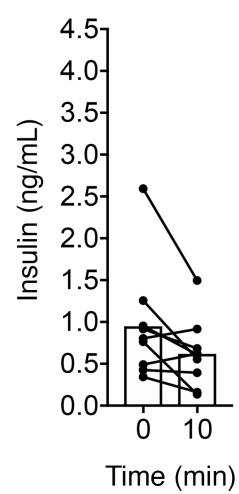

Gcg

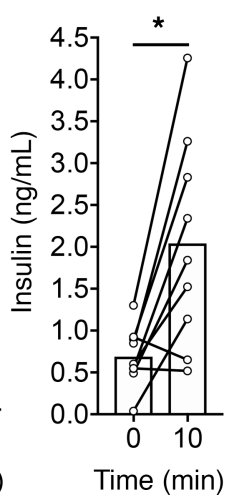

Figure 1. Exogenous glucagon stimulates insulin secretion and lowers glycemia. Low-dose $(20 \mu \mathrm{g} / \mathrm{kg})$ glucagon (A) increases glycemia and (B) does not stimulate insulin secretion in ambient-fed mice. High-dose $(1 \mathrm{mg} / \mathrm{kg})$ glucagon (C) lowers glycemia compared with PBS control and (D) stimulates insulin secretion in ambient-fed mice. ${ }^{*} P<0.05$ vs. PBS control (A and C) or 0-minute value (D); values are mean \pm SEM. Statistical tests: Student's paired $t$ test (B and $\mathbf{D})$ and 2-way ANOVA (A and $\mathbf{C}$ ). iAUC, incremental AUC.

concentrations ( $\sim 150 \mathrm{mg} / \mathrm{dL}$, Figure $2 \mathrm{C}$ ) without stimulating insulin secretion (Figure $2 \mathrm{D})$. Here, glucagon produced an initial rise in glycemia at 10 minutes that was accompanied by a robust increase in insulin secretion ( $\sim 5$-fold). Consequently, glucose values in mice treated with glucagon dropped below control values at subsequent time points. These data indicate that glucagon can produce a net decrease in glycemia in the context of glucose-stimulated $\beta$ cell activity.

We next tested the importance of ambient glucose per se on the insulinotropic and glycemic actions of glucagon. Ambient glycemia was reduced, while $\beta$ cell activation was retained by administering the sulfonylurea tolbutamide to fed mice. With this treatment glycemia was reduced to fasting levels $(\sim 75$ $\mathrm{mg} / \mathrm{dL}$ ) in fed mice, but drug-induced closure of $\mathrm{K}_{\text {ATP }}$ channels activated $\beta$ cells similar to what occurs during hyperglycemia. Administration of glucagon under these conditions produced a net decrease in glycemia (Figure 2E) along with a robust increase in insulin secretion (Figure 2F). These data highlight that the insulinotropic effects of glucagon are dependent on ambient glycemia only to the extent that this activates the $\beta$ cells; tolbutamide activation obviates the need for increased glycemia to permit glucagon stimulation of insulin release. Importantly, active $\beta$ cells induced by tolbutamide abolished any net elevation of blood glucose by glucagon.

To directly test the importance of $\beta$ cell glucagon activity on systemic glycemia, we selectively deleted insulinotropic receptors for glucagon on $\beta$ cells. Because our group and others have previously demonstrated that the insulinotropic properties of glucagon are mediated through both GCGR and GLP-1R in $\beta$ cells $(5,7,19)$, we used mice with $\beta$ cell-specific knockout of GCGR and GLP-1R (Gcgr:Glp1 $\gamma^{\beta \text { cell-/-) }}$ (5). Although administration of glucagon under prandial conditions lowers glycemia in WT mice (Figure 1B),

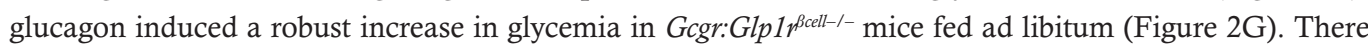




\section{WT mice - Fasted O/N}
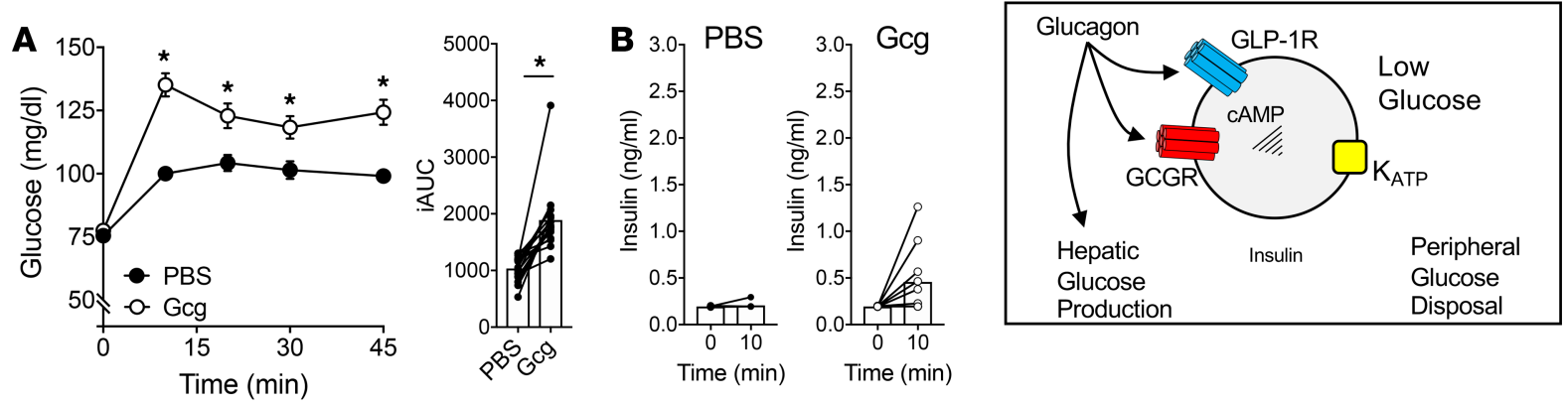

WT mice - Fasted O/N + Glucose
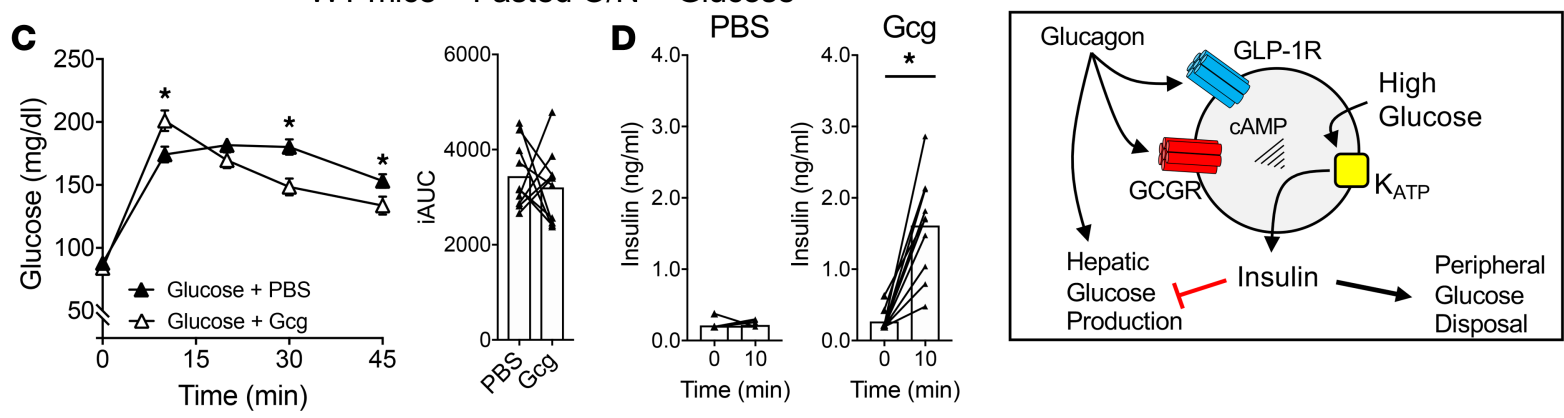

WT mice - Fed + Tolbutamide
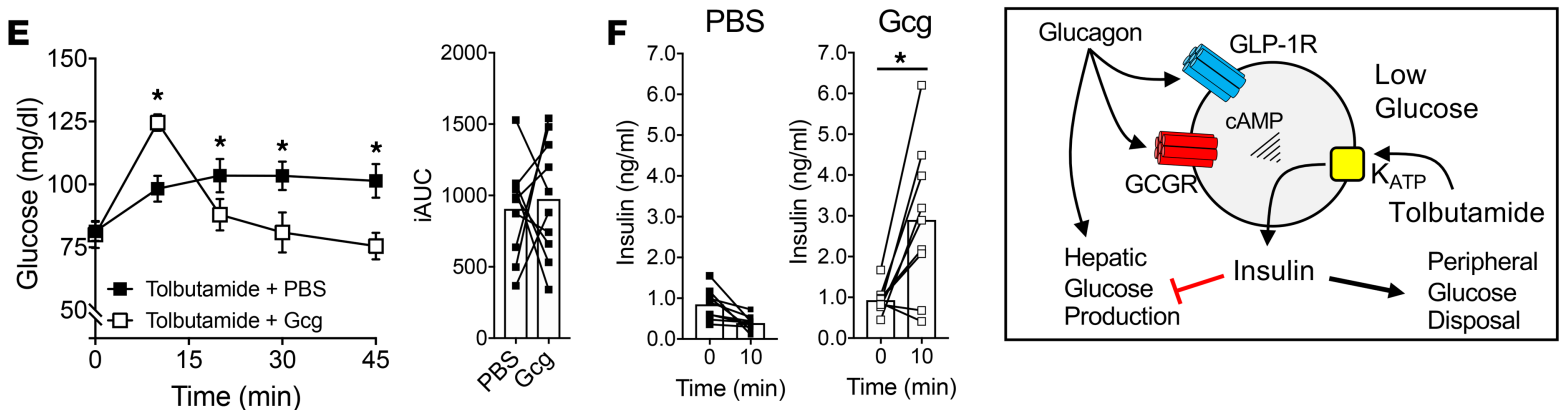

Glp1r:Gcgrßcell-- mice - Fed
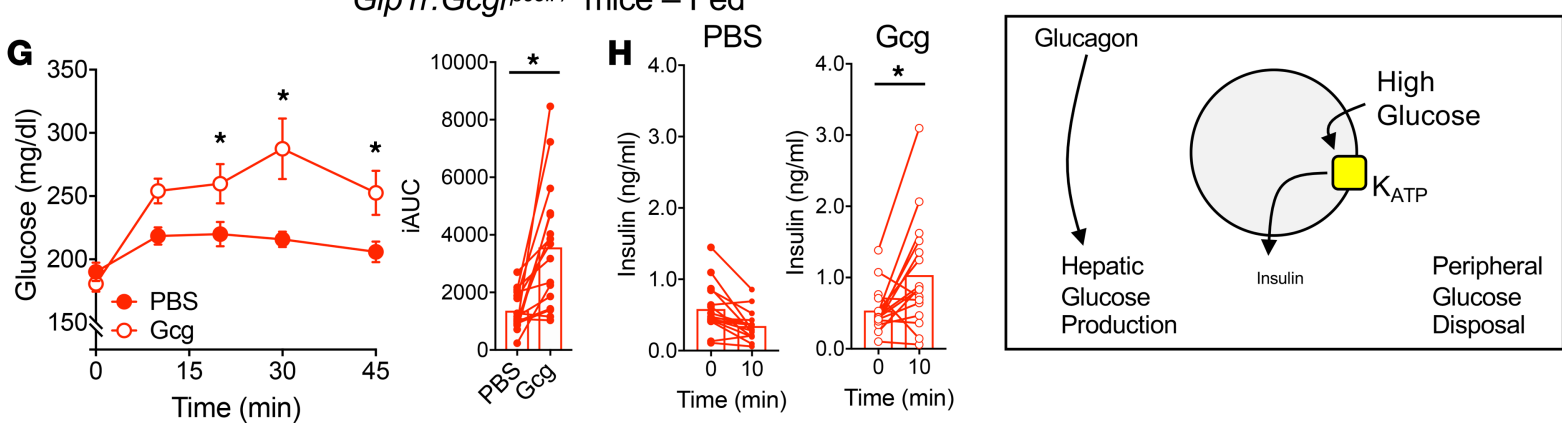

Figure 2. The glycemic effects of glucagon depend on $\boldsymbol{\beta}$ cell activity. (A and $\mathbf{B}$ ) High-dose (1 mg/kg) glucagon given to mice fasted overnight (A) increases plasma glucose and (B) does not stimulate insulin secretion. (C and $\mathbf{D})$ Coadministration of $1 \mathrm{mg} / \mathrm{kg}$ glucagon with $0.5 \mathrm{~g} / \mathrm{kg}$ glucose to mice fasted overnight (C) produces lower glycemia compared with glucose alone and (D) stimulates an increase of $~ 6$-fold in insulin secretion. (E and F) Ambient-fed mice treated with tolbutamide (100 mg/kg) to lower glucose to fasting levels respond to glucagon (1 mg/kg) with (E) lower glycemia and (F) increased insulin secretion of 3-fold. (G and $\mathbf{H})$ Glucagon (1 mg/kg) given to Glp1r Gcgr ${ }^{\beta c e l l-/-}$ mice $(\mathbf{G})$ increases glycemia and (H) produces a $~ 2$-fold increase in insulin secretion. ${ }^{*} P<0.05$ vs. PBS control $(\mathbf{A}, \mathbf{C}, \mathbf{E}$, and $\mathbf{G})$ or 0-minute value (D, F, and $\mathbf{H})$; values are mean \pm SEM. Statistical tests: Student's paired $t$ test $(\mathbf{B}, \mathbf{D}, \mathbf{F}$, and $\mathbf{H})$ and 2 -way ANOVA $(\mathbf{A}, \mathbf{C}, \mathbf{E}$, and $\mathbf{G})$.

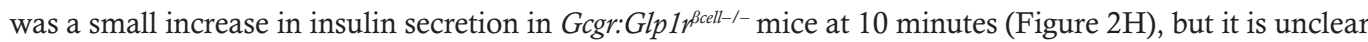
whether this was induced by the rise in glycemia or through extrapancreatic mechanisms that have been described for GLP-1 (20, 21). This rise in insulin was insufficient to prevent an elevation in glycemia. These data illustrate that the overall glycemic effects of exogenous glucagon are primarily dictated by the level of insulinotropic activity of glucagon in $\beta$ cells. 

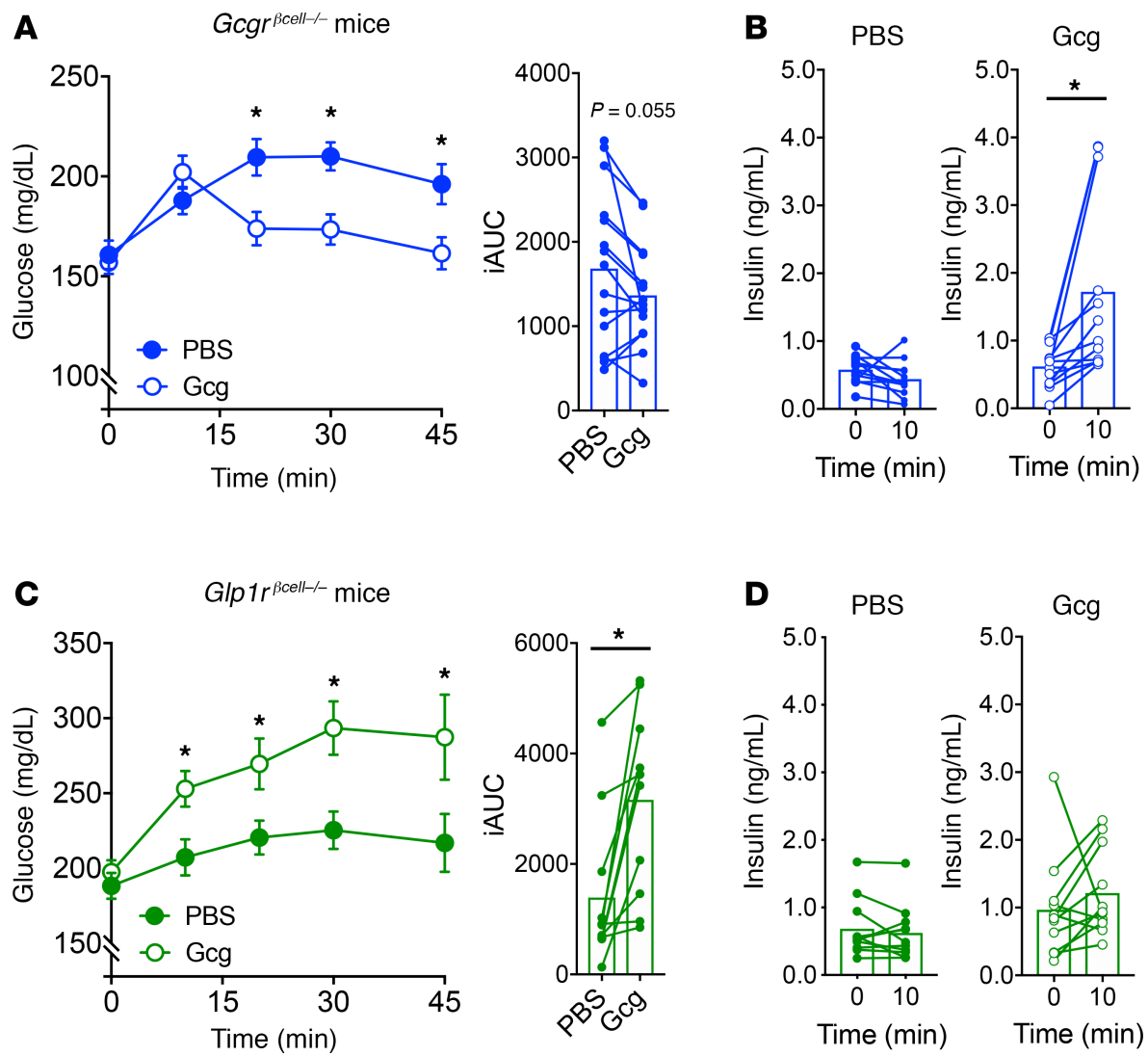

Figure 3. Glucagon requires the GLP-1R to lower glycemia and stimulate insulin secretion. (A and B) High-dose (1 mg/ kg) glucagon given to fed Gcgricell-/- mice. (A) Glucagon lowered glycemia and (B) stimulated insulin secretion in Gcgricell-/mice. (C and D) High-dose (1 mg/kg) glucagon given to fed Glp1r $r^{\text {Bcell-/- }}$ mice. (C) Glucagon raised glycemia and (D) did not stimulate insulin secretion in Glp1ricell-/- mice. ${ }^{*} P<0.05$ vs. PBS control (A and $\left.\mathbf{C}\right)$ or 0 -minute value (B); values are mean \pm SEM. Statistical tests: Student's paired $t$ test (B and $\mathbf{D})$ and 2-way ANOVA (A and $\mathbf{C})$.

Glucose-lowering effects of glucagon are dependent on $\beta$ cell GLP-1R. We have previously reported that glucagon-stimulated insulin secretion in $\beta$ cells is mediated through both GLP-1R and GCGR (5). To extend this finding to our in vivo model, we tested the importance of glucagon action on $\beta$ cells using single-deletion models of either GCGR ( $\left.G c g r^{\beta c e l l--}\right)$ or GLP-1R $\left(G l p 1 r^{\beta \text { cell- }--}\right)$. Glucagon lowered glycemia (Figure 3A) and induced a notable increase in insulin secretion (Figure 3B) in Gcgr $r^{\beta c e l l-/-}$ mice, indicating that $\beta$ cell GCGRs are dispensable for the glucose-lowering properties of glucagon. However, glucagon raised glycemia (Figure 3C) and failed to induce meaningful insulin secretion (Figure 3D) in Glp $11^{\beta \text { cell- }--}$ mice, demonstrating the necessity for the $\beta$ cell GLP-1R to mediate the glucose-lowering effects of glucagon. These data support our previous finding that the insulinotropic properties of glucagon are predominantly mediated through the GLP-1R (5).

$\beta$ cell GCGR enables sufficient insulin production to affect glycemia. Our findings in Gcgr $r^{\beta c e l l-1-}$ and Glp1 $\gamma^{\beta c e l l-1-}$ mice suggest that $\beta$ cell GCGR activity is mostly dispensable for insulin secretion. Yet, the promiscuity of glucagon and the compensatory mechanisms often observed in genetic models confound this interpretation. Therefore, we used a GCGR-specific agonist (GCGR-SA; 44-0410) in our mouse models to specifically interrogate the role of GCGR in $\beta$ cells for glucagon-stimulated insulin secretion. We have previously demonstrated that the GCGR-SA is specific for the GCGR in $\beta$ cells, has insulinotropic properties, and does not interact with the GLP-1R (5). Administration of the GCGR-SA increased glycemia (Figure 4A) and produced a modest increase in insulin secretion in fed WT mice compared with mice receiving a control injection (Figure $4, \mathrm{~B}$ and $\mathrm{C}$ ). This suggests that the small increase in GCGR-mediated insulin secretion is insufficient to reduce glycemia in vivo. Interestingly, administration of the GCGR-SA to $G c g \beta^{\beta c l l-1-}$ mice led to more pronounced hyperglycemia than in WT mice (Figure 4A), and although there was a significant increase of insulin secretion, it appeared to be secondary to the change in blood glucose; normalizing insulin to the robust increase in glycemia yielded no change compared to baseline (Figure 4D). 
A

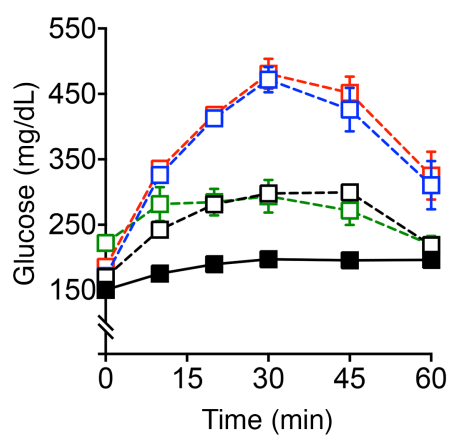

- WT - PBS

$\square$ - WT - GCGR Agonist

$\square \cdot$ Gcgr ${ }^{\beta c e l l-/}+$ GCGR Agonist

- - Glp1 $1 n^{\beta c e l l-1-}+$ GCGR Agonist

$\square \cdot$ Gcgr:Glp $1 n^{\text {icell-- }}+$ GCGR Agonist

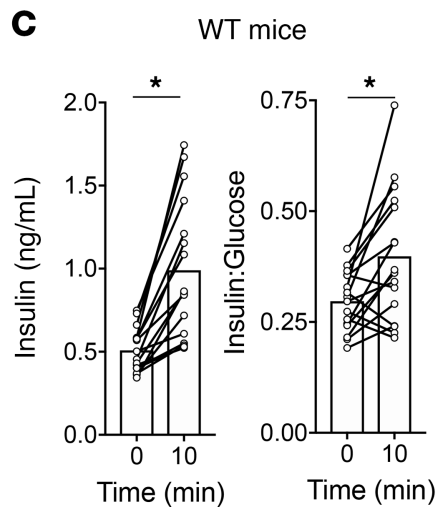

D Gcgr ${ }^{\mathrm{Bcll}-1-}$ mice
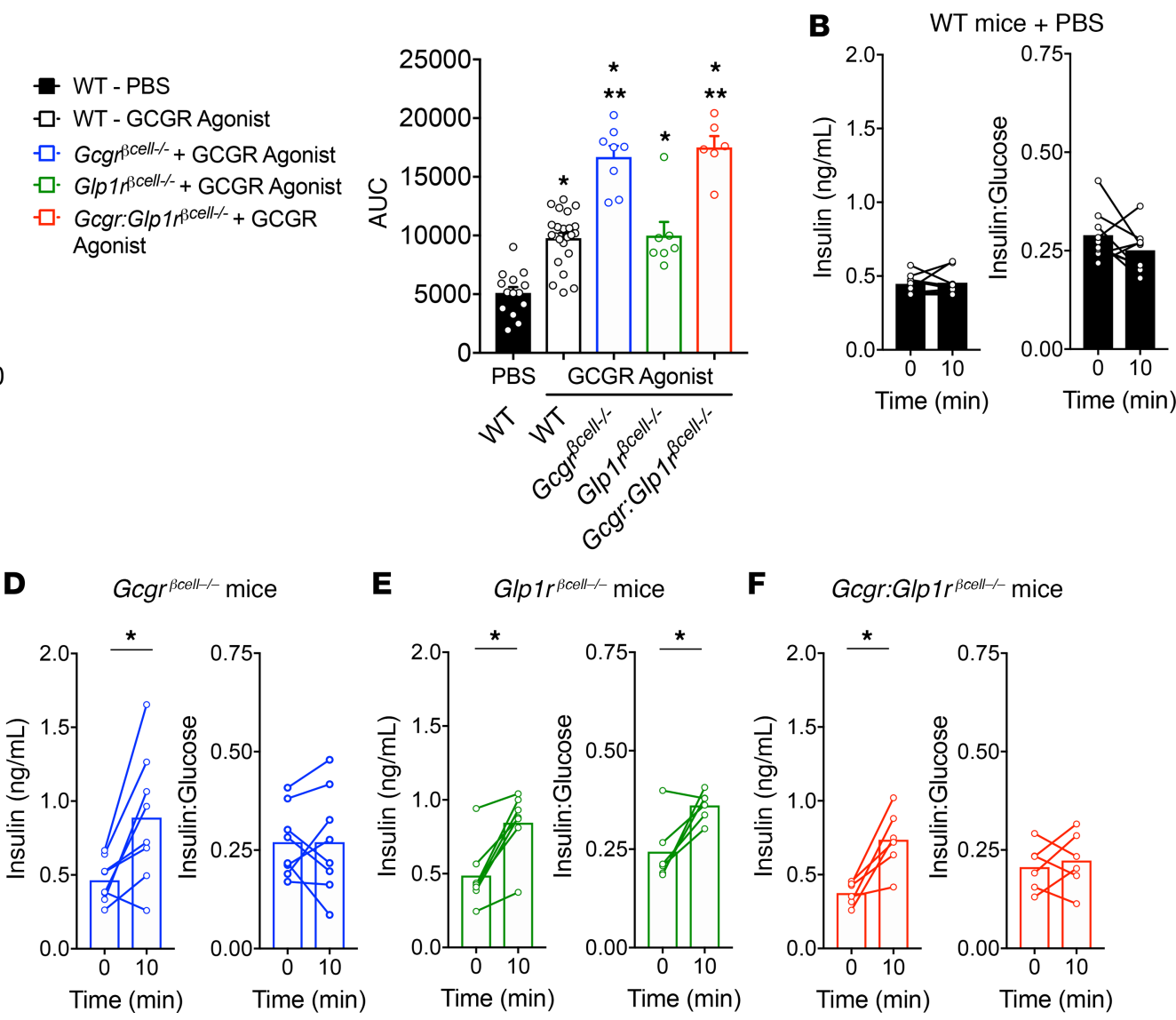

Figure 4. The $\boldsymbol{\beta}$ cell GCGR is required for the full insulinotropic effects of glucagon. (A) The glycemic response to a GCGR-specific agonist (GCGR-SA; 44-0410) in fed mice. Mice without the GCGR in $\beta$ cells demonstrated a much more robust glycemic response compared with WT or GIp1 $r^{\beta c e l l-/-}$ mice. The insulin response (left) and insulin/glucose ratio (right) in response to (B) PBS in WT mice or the GCGR-SA in (C) WT mice, (D) Gcgr ${ }^{\beta c e l l-/-}$ mice, (E) GIp1r $r^{\beta c e l l-/-}$ mice, and (F) Gcgr:Glp1 $r^{\beta c e l l-/-}$ mice. ${ }^{*} P<0.05$ vs. WT, PBS control (A) or 0-minute value (B-F); ${ }^{*} P<0.05$ vs. WT, GCGR-SA; values are mean \pm SEM. Statistical tests: Student's paired $t$ test (B-F) and 1-way ANOVA (A).

Administration of the GCGR-SA to Glp1ricell-- mice produced similar glycemic (Figure 4A) and insulin secretion profiles (Figure 4E) as in treated WT mice, indicating the specificity of the agonist for the GCGR. Moreover, normalizing insulin secretion to glycemia in either WT or Glp $1 r^{\beta \text { cell-1- }}$ mice produced a significant increase in values at 10 minutes (Figure 4, C and E), indicating a level of insulinotropic capability through the GCGR. Gcgr:Glp1 $\gamma^{\beta c e l l-1-}$ mice given the GCGR-SA had similar glycemic (Figure 4A) and insulin secre-

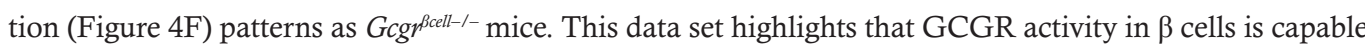
of independently stimulating insulin secretion but that this activity alone is unable to negate the hyperglycemic effects of hepatic glucagon action. Taken together, we conclude that GLP-1R is the predominant receptor that mediates glucagon-stimulated insulin secretion. Thus, although glucagon activity through the GCGR can stimulate insulin secretion, the contribution is minimal in the presence of an intact GLP-1R.

Mixed-nutrient meals stimulate both glucagon and insulin secretion. To determine the physiologic relevance of glucagon-stimulated insulin secretion, we first sought to demonstrate coordinated cosecretion of glucagon and insulin in mice. It has long been known that following the consumption of mixed nutrients, humans secrete both glucagon and insulin. Consistent with this, oral gavage of a mixed-nutrient solution (Ensure) to WT mice significantly increased both insulin (Figure 5A) and glucagon (Figure 5B). In contrast, an oral glucose gavage $(1.5 \mathrm{~g} / \mathrm{kg}$ ) led to an increase in plasma insulin only, but not glucagon (Figure 5, A and B). The stimulation of both insulin and glucagon by mixed-nutrient intake became more apparent when portal vein samples were assayed (Figure $5 \mathrm{C}$ ). The substantial increase in both insulin and glucagon in the venous pool immediately downstream from the islets reflects the typical response to meals and demonstrates that the prandial setting is one where endogenous glucagon can contribute to insulin secretion.

A limitation to using mixed-meal gavages to query the importance of $\alpha$ cell-derived glucagon for insulin secretion and glucose homeostasis is the confounding contribution of gut-derived incretin peptides. 


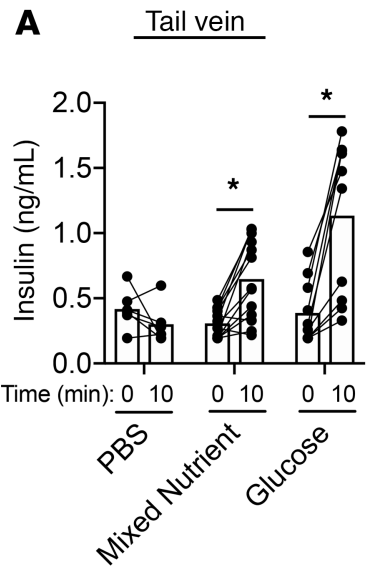

B Tail vein

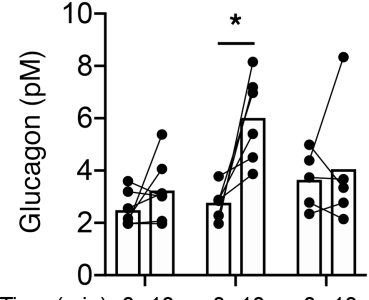

Time (min): $010 \quad 010 \quad 010$
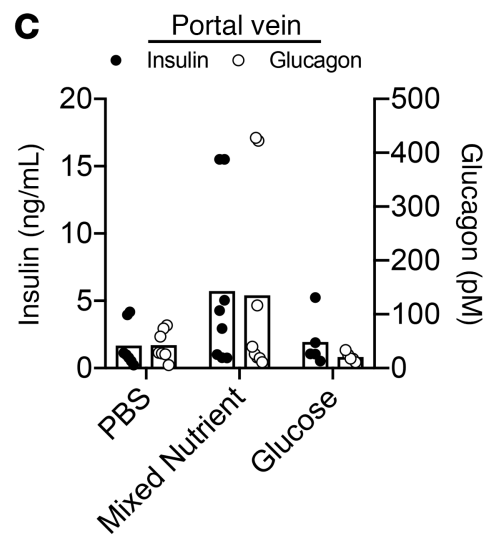
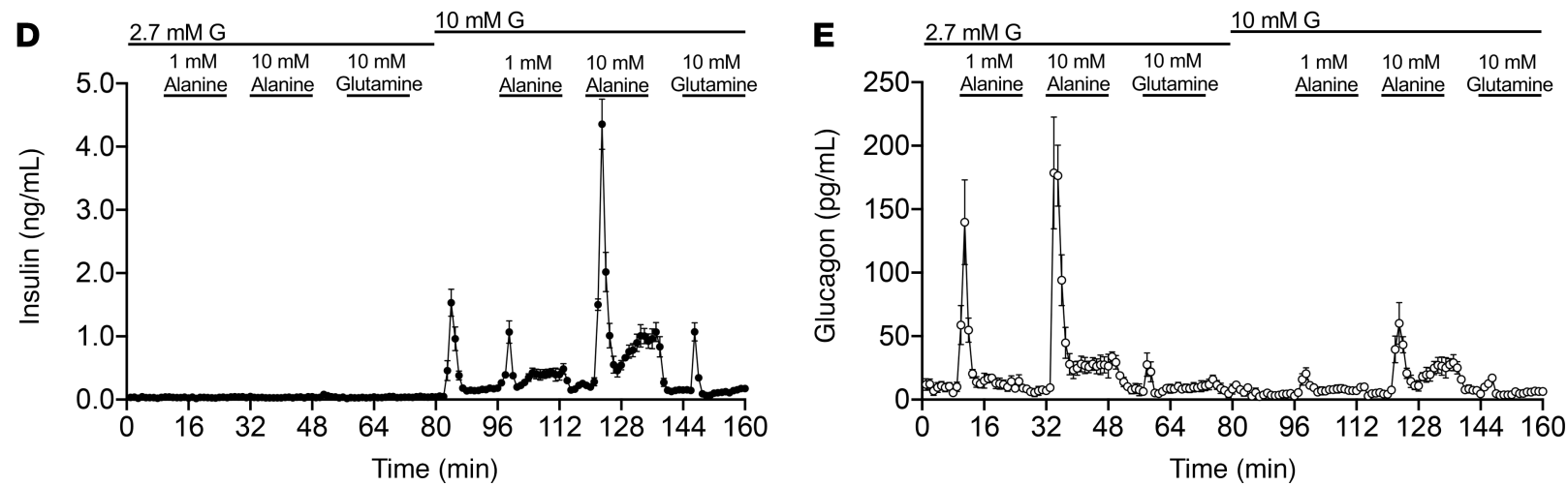

Figure 5. A mixed-nutrient meal stimulates glucagon and insulin secretion in mice. (A-C) WT mice were given an oral gavage of PBS, liquid Ensure (mixed nutrient, $10 \mathrm{~mL} / \mathrm{kg}$ ), or glucose $(1.5 \mathrm{~g} / \mathrm{kg}$ ). (A) Plasma insulin concentrations sampled from the tail vein at 0 and 10 minutes. (B) Plasma glucagon concentrations sampled from the tail vein at 0 and 10 minutes. (C) Insulin (closed circles) or glucagon (open circles) concentrations sampled from the portal vein at 10 minutes. (D) Insulin secretion in WT islets. (E) Glucagon secretion in WT islets. ${ }^{*} P<0.05$ vs. control (A and $\left.\mathbf{B}\right) ;$ values are mean \pm SEM. Statistical tests: 2-way ANOVA (A-C).

In particular, we have previously demonstrated that GIP sensitivity is markedly enhanced in Gcgr:Glp1 $\gamma^{\text {scll-/- }}$ mice, our model of impaired $\alpha$ to $\beta$ cell communication (5). To allow for direct stimulation of $\alpha$ cells, independent of incretin input, we administered amino acids i.p. We previously observed that glutamine and arginine act as potent glucagon secretagogues (5). In addition, alanine has been tested in humans and also causes glucagon secretion in vivo $(22,23)$. Both alanine and glutamine play a significant role in shuttling carbon and nitrogen from peripheral tissues to the liver, while serving as major gluconeogenic substrates, highlighting that both amino acids have substantial metabolic roles. Therefore, we compared these 2 amino acids in perifusion to assess their effect on glucagon and insulin secretion (Figure 5, D and E). Neither alanine nor glutamine stimulated insulin secretion at a low-glucose conditions (Figure 5D), and the lack of a direct effect on $\beta$ cells implicates $\alpha$ cell input as necessary for their insulinotropic action (5). Alanine-stimulated glucagon secretion was much greater than glutamine-stimulated glucagon secretion at both low and high glucose, indicating that it is the more potent $\alpha$ cell secretagogue in mice (Figure 5E). Moreover, the increased effect of alanine on glucagon secretion at high glucose translated to a more robust stimulation of insulin secretion (Figure 5D). Based on this, we used alanine to stimulate glucagon secretion in vivo.

Endogenous, alanine-stimulated glucagon secretion requires $\beta$ cell activity for normal glucose homeostasis. Alanine

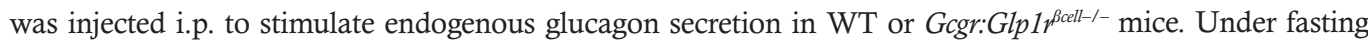
conditions, where $\beta$ cells are inactive (Figure 2A), alanine treatment in WT mice induced significant increases in glucagon and glycemia but did not induce insulin secretion (Figure 6, A-C). These results support roles for alanine as both a gluconeogenic substrate and glucagon secretagogue. Interestingly, administration of alanine to $\mathrm{Gcg}^{-1-}$ mice, which do not make any proglucagon products (24), failed to increase glycemia (Supplemental Figure 2), highlighting the necessity of glucagon to facilitate alanine metabolism into glucose. Fasted Gcgr:Glp1r $r^{\text {Bcll-1-- }}$ mice had a similar response to exogenous alanine: elevated glycemia without changes in insulin but robust increases in glucagon secretion (Figure 6, D-F). We then tested the effect of alanine-stimulated 
A

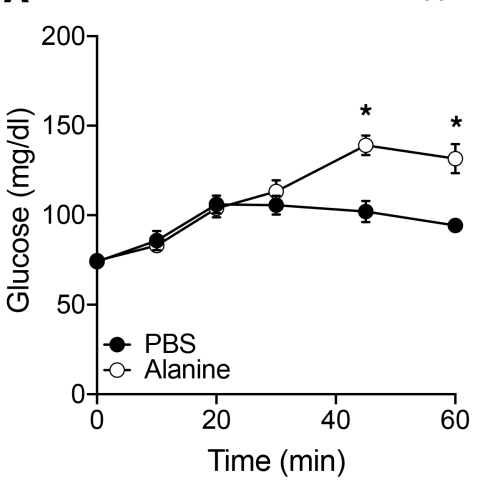

D

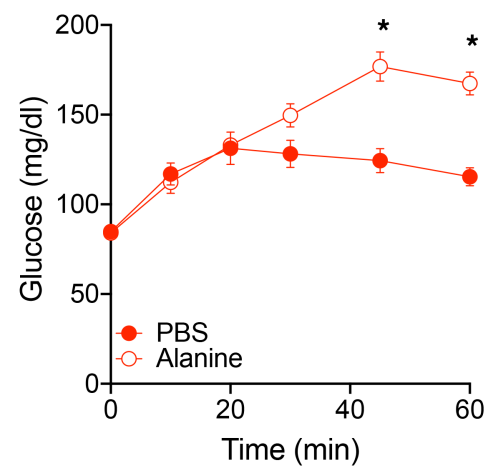

G

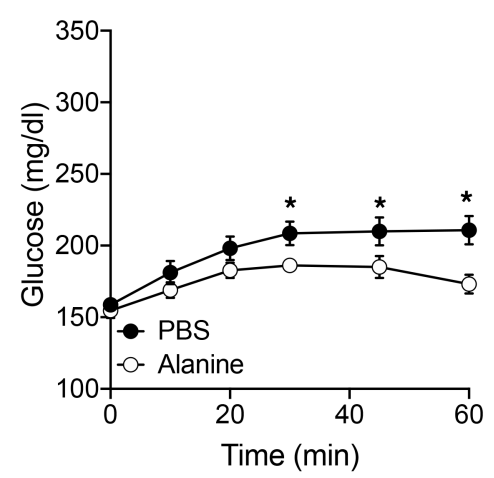

J

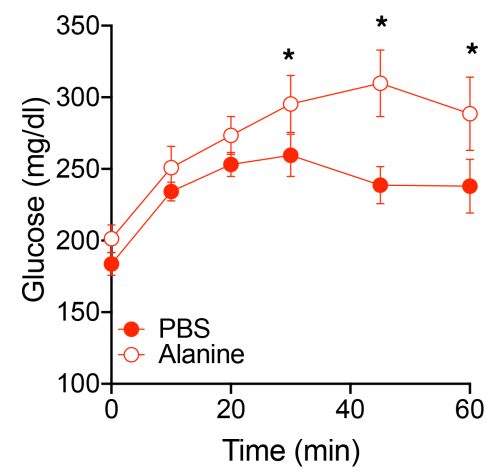

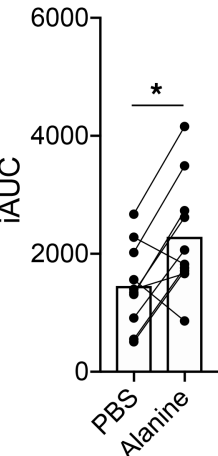

mice - fasted

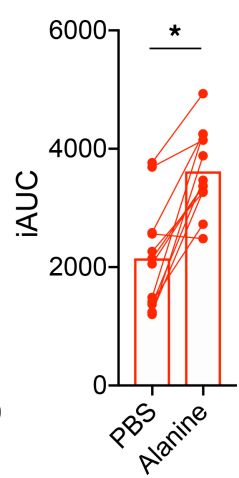

WT mice - fed

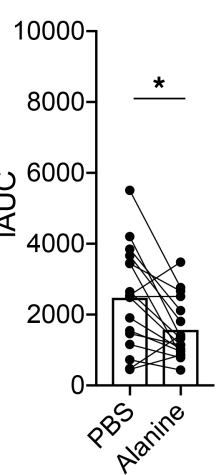

Gcgr:Glp1r $r^{\beta c e l l-1}$ mice - fed

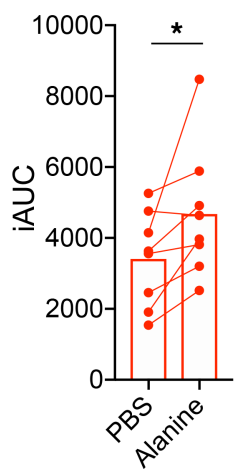

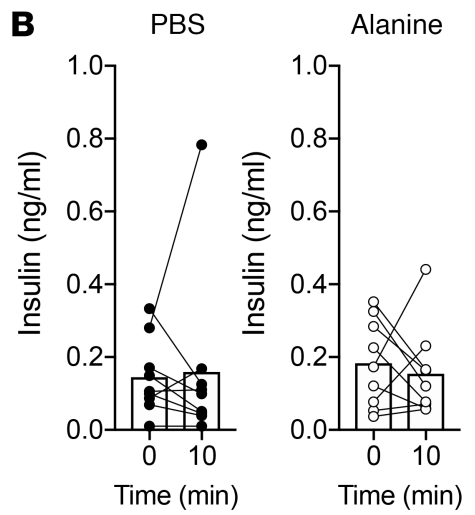
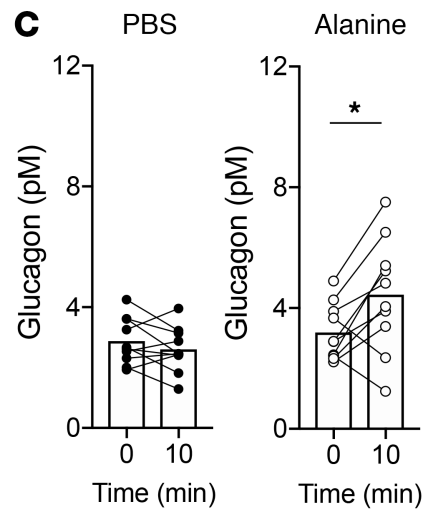

E
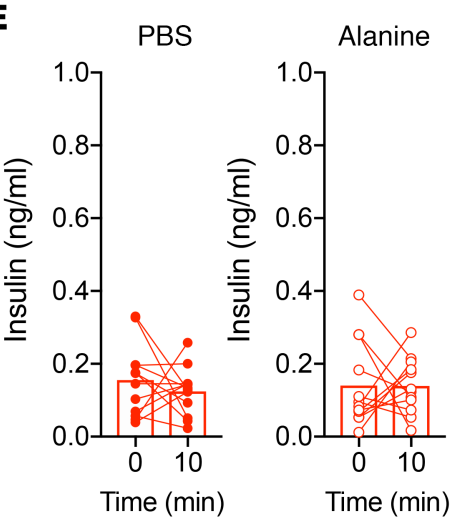

F PBS

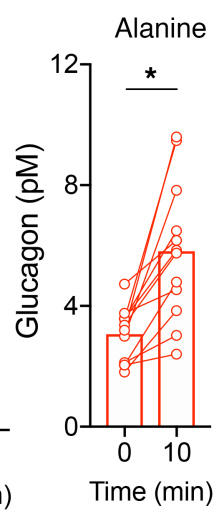

H

PBS

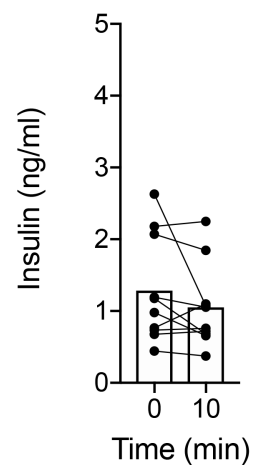

Alanine

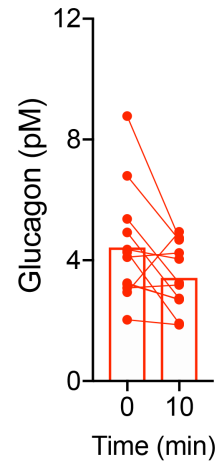

PBS

Alanine
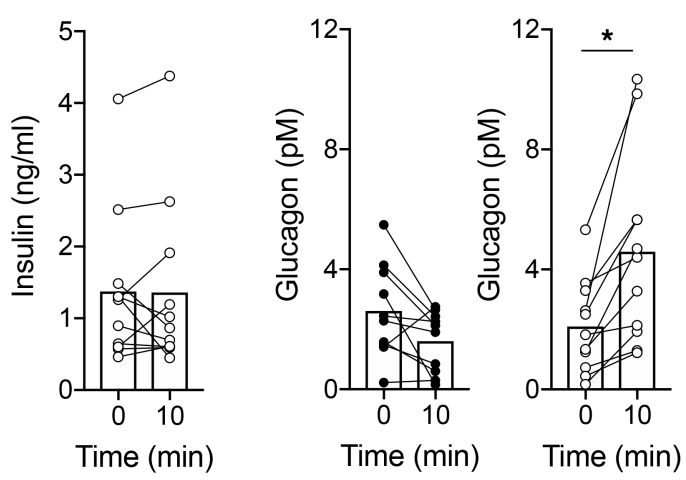

$\mathbf{K}$

PBS

Alanine

L PBS

Alanine
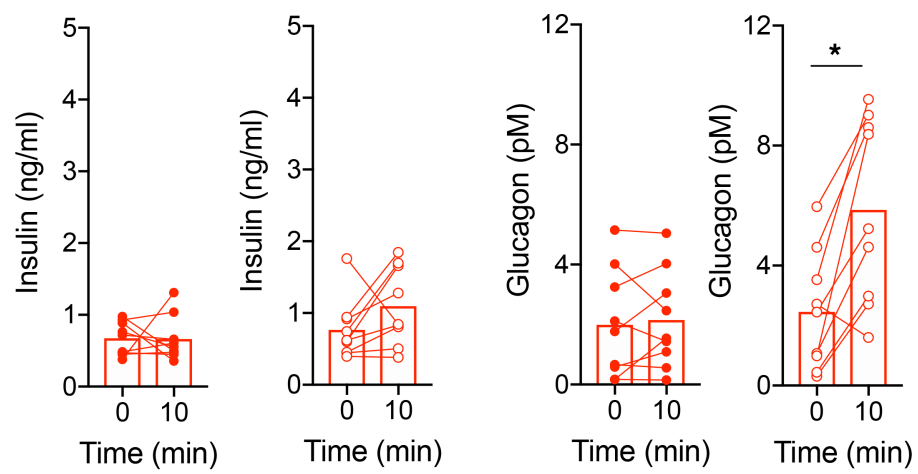

Figure 6. Endogenous glucagon secretion by alanine requires $\beta$ cell activity to lower glycemia. (A) Glucose, (B) insulin, and (C) glucagon concentrations in WT mice fasted overnight and injected i.p. with alanine $(0.325 \mathrm{~g} / \mathrm{kg}$ ). (D) Glucose, (E) insulin, and (F) glucagon concentrations in Gcgr:Glp1ricell-/- mice fasted overnight and injected i.p. with alanine. (G) Glucose, (H) insulin, and (I) glucagon concentrations in fed WT mice injected i.p. with alanine. (J) Glu-

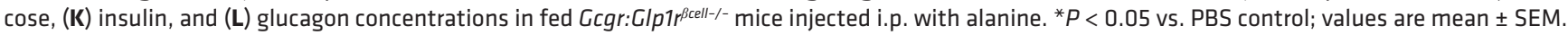
Statistical tests: Student's paired $t$ test (B, C, E, F, H, I, K, and $\mathbf{L}$ and iAUC in $\mathbf{A}, \mathbf{D}, \mathbf{G}$, and J) and 2-way ANOVA (A, D, G, and J). 
glucagon secretion in the fed state, where $\beta$ cells are capable of responding to glucagon (Figure 1C). Here, alanine decreased glycemia in WT mice (Figure 6G). Although there was no detectable increase in insulin secretion (Figure $6 \mathrm{H}$ ), glucagon secretion was significantly elevated (Figure 6I). This finding demonstrates that increased endogenous glucagon production can lower glycemia when $\beta$ cells are active, similar to our results with exogenous glucagon. To isolate the contribution of $\beta$ cells in this paradigm, we tested alanine treatment in fed Gcgr:Glp1 $\beta^{\beta \text { cell-1- }}$ mice. In the setting of impaired $\alpha$ cell/ $\beta$ cell signaling, alanine significantly increased glycemia (Figure 6J). Although there was no significant increase of plasma insulin, but a rise in glucagon, in WT mice (Figure 6, K and L), the effect of alanine to lower glycemia in WT mice, while raising glycemia in Gcgr:Glp1 $r^{\beta c e l l-1-}$ mice, implicates a role for glucagon-stimulated insulin secretion. We reasoned that the inability to detect an insulin response to alanine in WT mice was due to the combination of a weak stimulus and temporal resolution. To this end, we coadministered alanine and glucose $(1.5 \mathrm{mg} / \mathrm{kg})$ as a means of providing a stronger $\beta$ cell stimulus. In WT mice, alanine decreased the glycemic AUC and robustly increased insulin secretion beyond glucose alone (Supplemental Figure 3, A and B). Importantly, Gcgr:Glp1 $r^{\text {Bsell-/- }}{ }^{\text {mice }}$ responded to alanine with a higher glycemic AUC and failed to secrete insulin beyond that induced by glucose alone (Supplemental Figure 3, C and D). Taken together, our findings demonstrate that endogenous glucagon secretion decreases glycemia when $\beta$ cells are active but has an unopposed action on hepatic glucose output when glucose concentrations are low and potentiation of insulin secretion is muted.

\section{Discussion}

The findings described herein demonstrate a potentially novel aspect of glucagon action in glucose homeostasis. Importantly, we demonstrate that in the fed state, glucagon promotes insulin release and contributes to control of prandial glycemic excursions. This role during feeding runs counter to the well-described actions of glucagon as a counter-regulatory factor that raises blood glucose. However, our results indicate that the conventional view of glucagon action describes only the physiology of the fasting or hypoglycemic states. Our data demonstrate marked meal-stimulated glucagon release and emphasize the importance of amino acids to stimulate $\alpha$ cells and potentiate insulin secretion. Overall, the results of our experiments define a dual regulatory role for glucagon in nutrient metabolism, one that is contingent on the state of energy intake.

Our findings corroborate recent findings from our group and others using in vitro systems to demonstrate that exogenous or endogenous glucagon stimulates insulin secretion and dictates $\beta$ cell tone and by extension the glycemic set point (5-7). Moreover, inhibiting $\alpha$ cell function through a strategy invoking Gi-coupled DREADD (designer receptors exclusively activated by designer drugs) technology recapitulated the impaired insulin secretion in response to glucose or amino acids we previously described (5), while showing this impaired in vivo glucose tolerance (25). We have built on these recent observations in this paper, using mostly experiments in intact animals to demonstrate the physiologic relevance of glucagon as a $\beta$ cell stimulus. Our data provide strong evidence that glucagon regulates insulin secretion in vivo but that this is dependent on the state of glycemia, or $\beta$ cell activation, similar to the incretins. The concordance between the effects of exogenous glucagon and endogenous peptide, secreted in response to alanine, support this conclusion. Moreover, the mixed-nutrient stimulus used in our experiments is a better reflection of physiologic responses to normal ingestion than oral glucose tolerance tests, which have been a favored method to interrogate glucose homeostasis. Finally, interruption of the receptors that mediate glucagon action supports an emerging consensus that it is $\beta$ cell GLP-1R and not GCGR that is most important for these prandial effects.

Glucagon activity has been a central component of agents designed to treat diabetes. There has been a steady effort to develop GCGR antagonists (GRAs) that can block glucagon stimulation of hepatic glucose output for several decades. Yet recently, GCGR agonism has been incorporated into MRAs that seem very promising for lowering both glycemia and body weight. To date, the concept of agonizing the GCGR with MRAs was to harness its effect on energy expenditure while buffering the hyperglycemic response of the liver with increased insulin secretion by GLP-1R or GIPR activity (9). However, recent advances in understanding glucagon action, including the data presented here, support the potential benefit of combining GCGR with GLP-1R agonism at the level of the $\beta$ cell, where recruitment of both receptors may produce greater insulin secretion.

Interestingly, our results also raise the possibility that the glucose-lowering mechanisms of GRAs occur through $\beta$ cell as well as hepatic actions. Previous studies demonstrated that GRAs have attenuated effects to lower glucose in Glp1r/- mice (26), supporting a contribution of this receptor, which is not expressed by murine hepatocytes (27), to the mechanisms of action of GRAs. Importantly, GRA treatment leads to supraphysiologic concentrations of circulating glucagon and GLP-1 (28), which would greatly increase the 
intra-islet concentration of GLP-1R ligands and facilitate enhanced $\alpha$ to $\beta$ cell communication and insulin secretion (5). Thus, the hypothesis that glucagon action on $\beta$ cell GLP-1Rs contributes to the glycemic lowering effects of GRAs is both tenable and worthy of testing.

Herein, we describe that insulinotropic actions of glucagon can counteract its effects to drive hepatic glucose output. We propose that the interaction of glucagon and insulin in the prandial state is responsible for the modest state of relative hyperglycemia that defines normal glucose tolerance. Although insulin has some effects to blunt glucagon-stimulated glycogenolysis in cultured hepatocytes (29-31), there is evidence that this response is maintained (32), or even amplified (33), following coadministration of the 2 hormones. In the prandial setting, the role of glucagon may be to shunt glucose absorbed from the GI tract past the liver, and promote glucose use and disposal by peripheral tissues, similar to the incretins. Consistent with this thesis, glucagon has recently been described to increase insulin sensitivity (32). Understanding the mechanisms by which glucagon-stimulated insulin secretion reduces glycemia is an essential next step into further understanding the complexity of glucagon's actions in metabolism.

\section{Methods}

Reagents. Glucagon was purchased from MilliporeSigma and prepared in $0.3 \%$ acetic acid. Tolbutamide was purchased from MilliporeSigma and stock was freshly prepared in DMSO and injected at $0.1 \%$ in PBS.

Animals. Experiments were performed in 12- to 24-week-old mice of the C57BL/6J background. Mice were housed under a 12-hour light/12-hour dark cycle and provided free access to a normal chow diet. WT mice were purchased from Jackson Laboratories or bred in-house. All mouse lines were generated and used as previously described $(5,34)$. Briefly, Gcgrt/fl and/or Glp $1 r^{f l / f l}$ mice were crossed with MIP-CreERT (MIP-Cre) mice to generate $\beta$ cell-specific deletion. Tamoxifen $(50 \mathrm{mg} / \mathrm{mL})$ was prepared in corn oil and $100 \mu \mathrm{L}$ was administered by oral gavage on 5 consecutive days. Tamoxifen-treated, cagematched mice with floxed alleles and $\mathrm{MIP}-\mathrm{Cr}^{+/+}$and tamoxifen-treated, age-matched $\mathrm{MIP}-\mathrm{Cr}^{\mathrm{Cr} /+}$ mice served as controls. Knockout was confirmed in a subset of mice based on our previously published findings $(5,34)$, with almost complete loss of Gcgr and 70\% reduction of Glp1r in whole islets constituting efficient deletion. Male mice (12-16 weeks old) were used for all experiments.

Glucagon, meal, and alanine tolerance tests. For fasting experiments, food was removed from mice overnight and experiments performed the following morning ( $\sim 16$ hours). All other experiments were performed in mice fed ad libitum. Glucagon was prepared in PBS and administered by i.p. injection at either $20 \mu \mathrm{g} / \mathrm{kg}$ or 1 $\mathrm{mg} / \mathrm{kg}$. For experiments using glucose and glucagon, glucagon was prepared in PBS containing glucose with an injected glucose concentration of $0.5 \mathrm{~g} / \mathrm{kg}$. For experiments using tolbutamide, tolbutamide $(100 \mathrm{mg} / \mathrm{kg})$ was injected i.p. 1 hour before glucagon injection. In experiments using GCGR-SA 44-0410, the agonist was prepared in PBS $(1 \mathrm{mg} / \mathrm{kg})$ and injected i.p. For meal tolerance tests, mice were fed by oral gavage with liquid Ensure $(10 \mathrm{~mL} / \mathrm{kg})$. For alanine tolerance tests, mice were injected i.p. with alanine prepared in PBS (325 $\mathrm{mg} / \mathrm{kg}$ ). Blood glucose was measured from the tail using a glucometer (Contour). Serum was collected using EDTA-coated capillary tubes (Sarstedt). Serum insulin and glucagon were measured by ELISA (Mercodia).

Islet perifusion. Islets were isolated from WT mice as previously described $(5,35)$. Islets were incubated overnight, and then islets were placed into chambers (100 islets/chamber) containing $2.7 \mathrm{mM}$ glucose KRPH buffer (140 mM NaCl, $4.7 \mathrm{mM} \mathrm{KCl}, 1.5 \mathrm{mM} \mathrm{CaCl}_{2}, 1 \mathrm{mM} \mathrm{NaH}_{2} \mathrm{PO}_{4}, 1 \mathrm{mM} \mathrm{MgSO}$, $2 \mathrm{mM} \mathrm{NaH}-$ $\mathrm{CO}_{3}, 5 \mathrm{mM}$ HEPES, and $1 \%$ fatty acid-free BSA; $\mathrm{pH}$ 7.4) with $100 \mu \mathrm{L}$ Bio-Gel P-4 Media (Bio-Rad). Islets were equilibrated in $2.7 \mathrm{mM}$ glucose $\mathrm{KRPH}$ for 48 minutes, then perifused with alanine or glutamine at 2.7 $\mathrm{mM}$ glucose and $10 \mathrm{mM}$ glucose at concentrations described in Figure 5, D and E.

Statistics. All data are presented as mean \pm SEM. Statistical analyses were performed using GraphPad Prism 7. A 2-tailed Student's $t$ test or 1- or 2-way ANOVA was performed, depending on the experimental design, with a Bonferroni's post hoc analysis. $P<0.05$ was used to determine statistically significant differences.

Study approval. All mouse procedures were approved and performed in accordance with the Duke University Institutional Animal Care and Use Committee.

\section{Author contributions}

MEC, DAD, and JEC designed and directed the study. RWC made conceptual contributions. BF developed and provided key reagents. MEC, JBW, JK, ANG, and BS performed experiments. MEC, DAD, and JEC wrote the manuscript. All authors reviewed the manuscript and provided final approval for submission. 


\section{Acknowledgments}

MEC received support from the NIH/National Institute of Diabetes and Digestive and Kidney Diseases (NIDDK) (F32 DK116542). DAD is supported by the NIH/NIDDK (R01 DK101991). JEC is supported by a career development award from the American Diabetes Association (1-18-JDF-017) and is a Borden Scholar.

Address correspondence to: Jonathan E. Campbell, 300 North Duke St., Durham, North Carolina 27701, USA. Phone: 919.684.4865; Email: jonathan.campbell@duke.edu.

1. Müller WA, Faloona GR, Aguilar-Parada E, Unger RH. Abnormal alpha-cell function in diabetes. Response to carbohydrate and protein ingestion. N Engl J Med. 1970;283(3):109-115.

2. Bock G, et al. The effect of DPP-4 inhibition with sitagliptin on incretin secretion and on fasting and postprandial glucose turnover in subjects with impaired fasting glucose. Clin Endocrinol (Oxf). 2010;73(2):189-196.

3. Carr RD, et al. Secretion and dipeptidyl peptidase-4-mediated metabolism of incretin hormones after a mixed meal or glucose ingestion in obese compared to lean, nondiabetic men. J Clin Endocrinol Metab. 2010;95(2):872-878.

4. Rauch T, et al. Linagliptin increases incretin levels, lowers glucagon, and improves glycemic control in type 2 diabetes mellitus Diabetes Ther. 2012;3(1):10.

5. Capozzi ME, et al. $\beta$ Cell tone is defined by proglucagon peptides through cAMP signaling. JCI Insight. 2019;4(5):126742.

6. Rodriguez-Diaz R, et al. Paracrine Interactions within the pancreatic islet determine the glycemic set point. Cell Metab. 2018;27(3):549-558.e4.

7. Svendsen B, et al. Insulin secretion depends on intra-islet glucagon signaling. Cell Rep. 2018;25(5):1127-1134.e2.

8. Campbell JE, Drucker DJ. Islet $\alpha$ cells and glucagon--critical regulators of energy homeostasis. Nat Rev Endocrinol. 2015;11(6):329-338.

9. Capozzi ME, DiMarchi RD, Tschöp MH, Finan B, Campbell JE. Targeting the incretin/glucagon system with triagonists to treat diabetes. Endocr Rev. 2018;39(5):719-738.

10. Cegla J, et al. Coinfusion of low-dose GLP-1 and glucagon in man results in a reduction in food intake. Diabetes. 2014;63(11):3711-3720.

11. Day JW, et al. A new glucagon and GLP-1 co-agonist eliminates obesity in rodents. Nat Chem Biol. 2009;5(10):749-757.

12. Bhat VK, Kerr BD, Flatt PR, Gault VA. A novel GIP-oxyntomodulin hybrid peptide acting through GIP, glucagon and GLP-1 receptors exhibits weight reducing and anti-diabetic properties. Biochem Pharmacol. 2013;85(11):1655-1662.

13. Finan B, et al. A rationally designed monomeric peptide triagonist corrects obesity and diabetes in rodents. Nat Med. 2015;21(1):27-36.

14. Gault VA, Bhat VK, Irwin N, Flatt PR. A novel glucagon-like peptide-1 (GLP-1)/glucagon hybrid peptide with triple-acting agonist activity at glucose-dependent insulinotropic polypeptide, GLP-1, and glucagon receptors and therapeutic potential in high fat-fed mice. J Biol Chem. 2013;288(49):35581-35591.

15. Chen $\mathrm{M}$, et al. Increased glucose tolerance and reduced adiposity in the absence of fasting hypoglycemia in mice with liver-specific Gs alpha deficiency. J Clin Invest. 2005;115(11):3217-3227.

16. Rossi M, et al. Hepatic Gi signaling regulates whole-body glucose homeostasis. J Clin Invest. 2018;128(2):746-759.

17. Gelling RW, et al. Lower blood glucose, hyperglucagonemia, and pancreatic alpha cell hyperplasia in glucagon receptor knockout mice. Proc Natl Acad Sci USA. 2003;100(3):1438-1443.

18. Campbell JE, Drucker DJ. Pharmacology, physiology, and mechanisms of incretin hormone action. Cell Metab. 2013;17(6):819-837.

19. Moens K, Flamez D, Van Schravendijk C, Ling Z, Pipeleers D, Schuit F. Dual glucagon recognition by pancreatic beta-cells via glucagon and glucagon-like peptide 1 receptors. Diabetes. 1998;47(1):66-72.

20. Knauf C, et al. Brain glucagon-like peptide-1 increases insulin secretion and muscle insulin resistance to favor hepatic glycogen storage. J Clin Invest. 2005;115(12):3554-3563.

21. Jessen L, et al. Central nervous system GLP-1 receptors regulate islet hormone secretion and glucose homeostasis in male rats. Endocrinology. 2017;158(7):2124-2133.

22. Müller WA, Faloona GR, Unger RH. The effect of alanine on glucagon secretion. J Clin Invest. 1971;50(10):2215-2218.

23. Wise JK, Hendler R, Felig P. Evaluation of alpha-cell function by infusion of alanine in normal, diabetic and obese subjects. N Engl J Med. 1973;288(10):487-490.

24. Chambers AP, et al. The role of pancreatic preproglucagon in glucose homeostasis in mice. Cell Metab. 2017;25(4):927-934.e3.

25. Zhu L, et al. Intra-islet glucagon signaling is critical for maintaining glucose homeostasis. JCI Insight. 2019;5:127994.

26. Gu W, et al. Glucagon receptor antagonist-mediated improvements in glycemic control are dependent on functional pancreatic GLP-1 receptor. Am J Physiol Endocrinol Metab. 2010;299(4):E624-E632.

27. Panjwani N, et al. GLP-1 receptor activation indirectly reduces hepatic lipid accumulation but does not attenuate development of atherosclerosis in diabetic male ApoE(-/-) mice. Endocrinology. 2013;154(1):127-139.

28. Pearson MJ, Unger RH, Holland WL. Clinical trials, triumphs, and tribulations of glucagon receptor antagonists. Diabetes Care. 2016;39(7):1075-1077.

29. Pilar López M, Gómez-Lechón MJ, Castell JV. Role of glucose, insulin, and glucagon in glycogen mobilization in human hepatocytes. Diabetes. 1991;40(2):263-268.

30. Ikezawa Y, et al. Insulin inhibits glucagon-induced glycogenolysis in perivenous hepatocytes specifically. J Lab Clin Med. 2001;138(6):387-392.

31. Hartmann H, Probst I, Jungermann K, Creutzfeldt W. Inhibition of glycogenolysis and glycogen phosphorylase by insulin and proinsulin in rat hepatocyte cultures. Diabetes. 1987;36(5):551-555. 
32. Kim T, et al. Hepatic glucagon receptor signaling enhances insulin-stimulated glucose disposal in rodents. Diabetes. 2018;67(11):2157-2166.

33. Pedersen C, Bouman SD, Porsgaard T, Rosenkilde MM, Roed NK. Dual treatment with a fixed ratio of glucagon and insulin increases the therapeutic window of insulin in diabetic rats. Physiol Rep. 2018;6(6):e13657.

34. Smith EP, et al. The role of $\beta$ cell glucagon-like peptide-1 signaling in glucose regulation and response to diabetes drugs. Cell Metab. 2014;19(6):1050-1057.

35. Lamont BJ, Li Y, Kwan E, Brown TJ, Gaisano H, Drucker DJ. Pancreatic GLP-1 receptor activation is sufficient for incretin control of glucose metabolism in mice. J Clin Invest. 2012;122(1):388-402. 